\title{
City planning parameters of public hearings project
}

\author{
Nina Danilina ${ }^{1, *}$, Zinaida Ivanova ${ }^{1}$, and Michail Slepnev ${ }^{1}$ \\ ${ }^{1}$ Moscow State University of Civil Engineering, 129337, Yaroslavskoe sh., 26 Moscow, Russia
}

\begin{abstract}
Public hearings are one of the most important parts of urban management process that provide citizens involvement in development of urban territories. The article devotes to the question of evaluation of the Project that will be discussed on public hearings. Authors offer the method of evaluation of the sustainability of the Project in accordance with main principles of Sustainable urban design conception. The main aim is to make effective urban planning decision that will provide both interests of investors and citizens on the issue of realization of an urban project. The implementation of the developed method is directed on increasing the quality of urban environment, solving social conflict situations, and improving the urban management system.
\end{abstract}

\section{Introduction}

The modern city development is impossible without recognition of a right of each person to a comfortable and safe living environment. For this reason, the participation of city residents in the process of building and development of urban areas they are living at becomes an important phase of urban design. It is particularly relevant for Russia, where the procedure and the results of public hearings related to city projects is subjected to serious criticism, either from residents or experts [1-3].

The main problem that nowadays affects the effectiveness of public hearings in our country is the often conflict between the interests of investors aimed to get the maximum profit from the development of the territory and residents expectations and needs. Providing a way to evaluate the effect of the Projects presented at public hearings is becoming relevant for the sustainable development of cities and settlements [4-6].

Each country has developed and applied its own context dependent procedure for effective public hearings. They differ in procedure and implementation, but have a common goal - making decisions on the development of the living environment, that both provide current needs of the population and create conditions for its future development [7-9]. Essentially, the Concept of Sustainable Development of Urban Areas being based on the balance of three main aspects, such as social, economic and environmental, provides a possibility to regard them as evaluation factors for correct Project allocation [10-12].

It is suggested to measure the effective consideration of the main sustainable development aspects on the basis of town-planning system of criteria related to the Project

\footnotetext{
* Corresponding author: author@email.org
} 
submitted to public hearings. On the one hand, such set of criteria can provide an integrated approach to the description and presentation of this Project. On the other hand, it can be used to assess the specific characteristics of the Project, which should provide for the final decision on the results of public hearings $[13,14,15]$.

\section{Methods}

The main urban planning goal of public hearings is to make effective decisions on the development of the settlement system by optimizing the urban development construction, improving urban and rural settlements, developing engineering, transport and social infrastructures, rational environmental management, preserving historical and cultural heritage objects and protecting the environment to ensure favorable conditions for life, work and recreation.

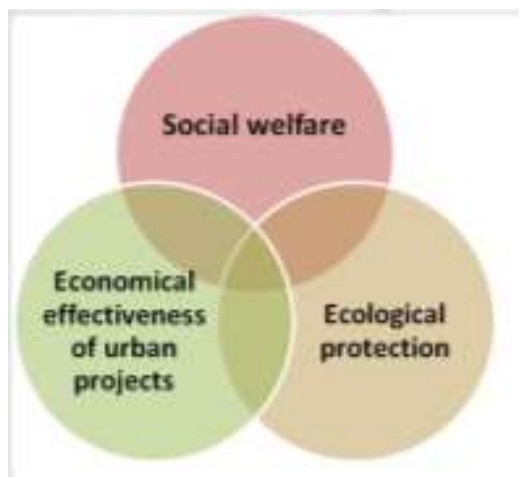

Fig. 1 Model of public hearing Project sustainability.

In order to achieve this goal, first of all it was developed the Model of public hearing Project sustainability, based on the traditional presentation approach (Figure 1). It illustrates that each of the aspects of sustainable development determines the urban development effect of the Project implementation.

The economic aspect determines the efficiency of a Public Hearing Project implementation, rational and expedient land use, provides solutions for the basic problems of the employment, inequality and lack access of the population to urban areas, effects the investment attractiveness of the project and improving the image of the city.

The social aspect covers the creation of social-oriented parameters of the population vital activities aimed to improve quality of life and standard general conditions of everyday life and labour, providing the necessary infrastructure objects and opportunities for its use for various groups of the population.

The environmental aspect implies planning appropriate measures aimed at reducing environmental pollution, rational choice monitoring and of different protection activities, developing temporary steps to reduce pollution in those areas where excess permissible concentrations have been identified, checking compliance with the standards and quality regulations of a natural object.

The next step is to choose a set of urban criteria that can define the essence of the theoretical Model. To select criteria, the main assess parameters of the Model were systematized on figure 2 .

Economical effectiveness of urban project assessment parameters:

1. Spatial planning development requirements of the territory as a process and at the same time the result that determines the quality of the settlement system and the urban 
environment. The evaluation criteria for this parameter can be divided into the following groups:

a) settlement system criteria:

- compliance of the Project to general strategy for regional settlement development planning;

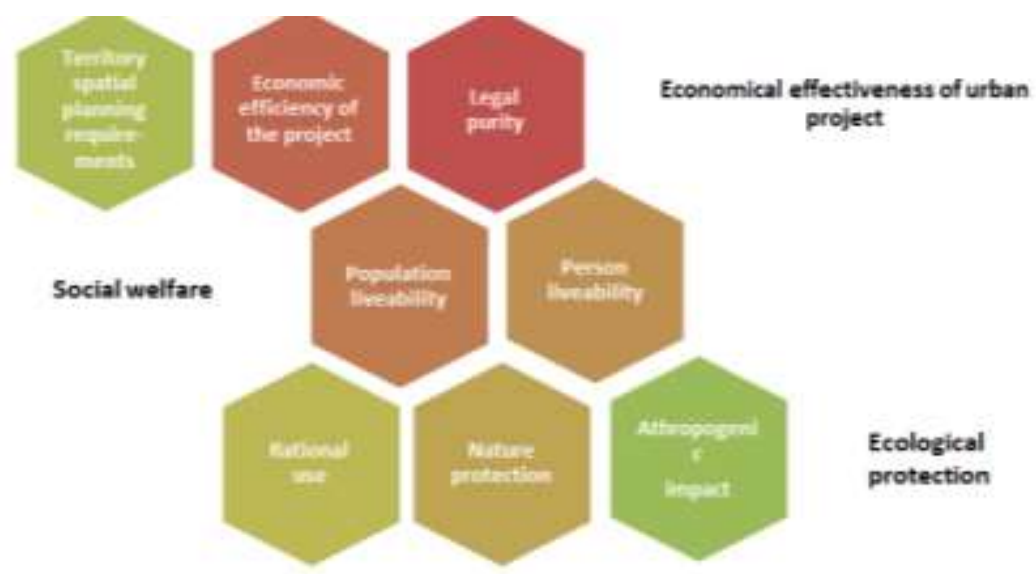

Fig. 2 Model assessment parameters composition.

- population distribution over the district, municipality, cities, subjects of the Russian Federation;

- dynamics of population concentration at project implementation (increase in population density, population focus points);

- conformity of the city and districts to demographic carrying capacity in terms of the maximum sustainable population size;

- compliance of the Project to standardized indicators of building density.

b) Development of the system of infrastructural objects criteria

- dynamics of the density of infrastructural objects on the territory unit;

- spatial-time accessibility of infrastructural objects.

c) Transportation system criteria

○ dynamics of the density of road and street network;

○ dynamics of density of passenger transport, km / sq. km;

- dynamics of the total mobility structure of the population.

○ engineering supply system;

- choice of energy sources;

o the use of energy-saving technologies;

$\circ$ the cost of engineering support.

2. Economic efficiency parameter determines the role of the Project in the development of the economic potential of the settlement and its innovative development. It can be evaluated by the following criteria:

- compliance of land use to the interests of the city;

- development and potential level of the territory;

o the investment value of the Project;

$\circ$ the ratio of the existing level of the area resource consumption to the designed object;

○ self-sufficiency of the urban environment;

o operational costs of the urban environment maintaining;

○ the growth of business activity and improvement of the investment climate; 
- the growth capitalization of residential and commercial real estate;

$\circ \quad$ the growth of rental rates for real estate.

3. Legal parameter determines the legal purity of the Project. It can be evaluated by the following criteria:

- compliance of the Project to the existing urban planning documentation;

- compliance of the Project to the existing urban planning documentation;

- compliance of the Project to the current legislation and the Constitution of the country related to the respect of the fundamental rights of each person.

Social aspect assessment parameters provide for the role of the Project in ensuring social progress. The assessment parameters of such progress followed by relative evaluation criteria are as follows:

1. Population livability:

○ social significance of the project;

- dynamics of population density, people / ha;

○ impact on employment patterns;

$\circ$ quality and safety of living environment.

2. Person livability

- dynamics of services provision for each population group;

- dynamics of favorable living conditions (well-maintained housing, provision of a standard set of socio-cultural services, communication, Internet, etc.);

- respect for the rights of each person: equality in the use of urban areas, free access to services.

Environmental aspect assessment parameters provide for the correspondence of the Project nature use (соотвествие характера природопользования природно-ресурсным условиям) to natural resource conditions and can be evaluated upon the following criteria:

1. Rational use of natural resources

- ecological capacity of the territory;

- self-cleaning potential of the atmosphere;

o operational reserves of groundwater;

2. Nature protection

- correspondence of the environmental quality to regular standards;

- surface runoff module;

3. Anthropogenic impact consideration

- historical, cultural, natural value preserve;

- distribution areas of various types of pollution.

Definition of a numerical parameters system and criteria for their evaluation involves an in-depth analysis of the Project submitted to public hearings, including the aim to identify its weak and strong points.

\section{Implementation}

The implementation of the developed system of parameters in the practice of holding public hearings is expected in 2 stages:

- At the stage of preparation of the Project for public hearings. During this period, the parameter system acts as a generalized characteristic of the Project, expressed in qualitative or quantitative form. It will help to bring objective information to the participants of public hearings on the basis of the justification of the Project's contribution to the sustainable development of a settlement or a specific territory

- At the stage of evaluating the results of public hearings, the system of parameters allows an objective assessment of the comments received from the participants of the hearing. 
In either case, the assessment is carried out on the basis of a comparison of integral indicators for each of the parameters. The system of these integral criteria is presented in Figure 3.

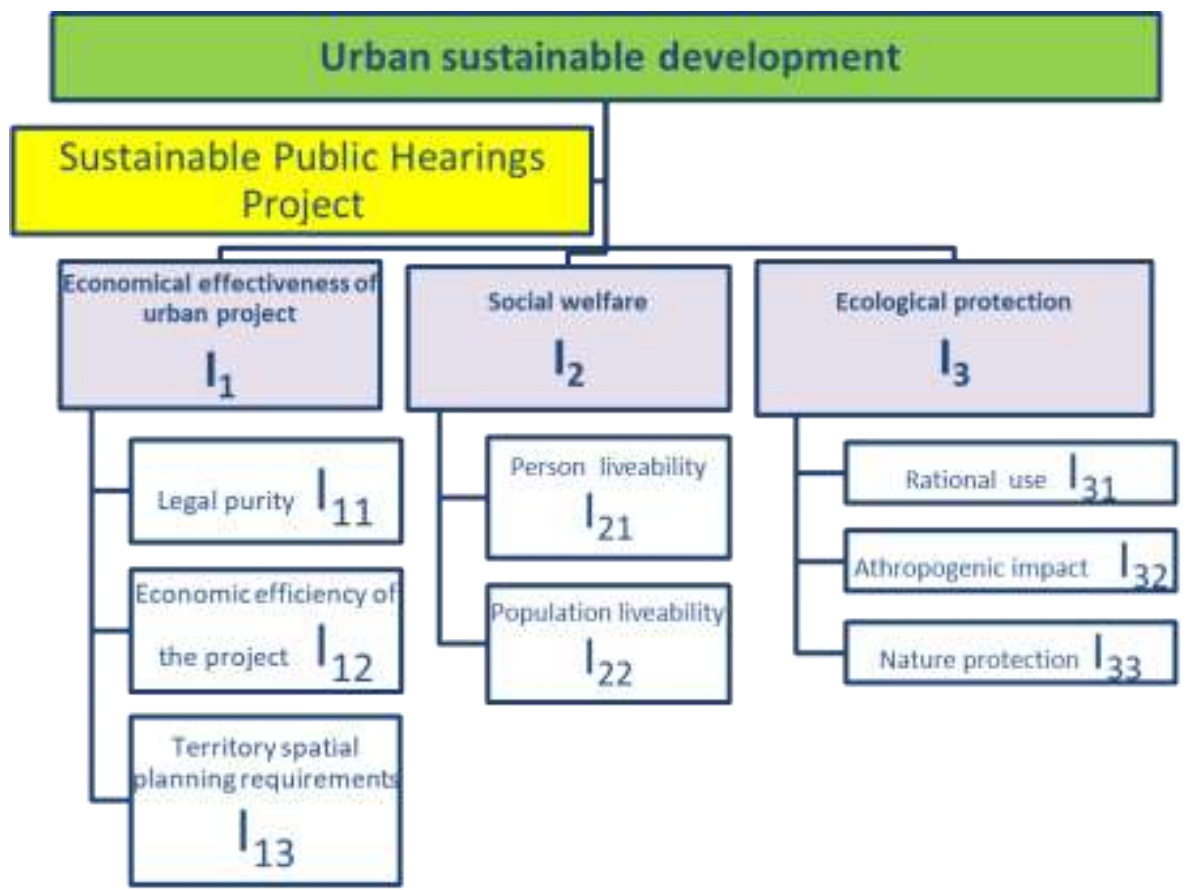

Fig. 3 The system of integrated criteria.

The paper proposes the use of a graph-analytical method that allows visual presentation of the assessment results using a grid, each axis of which represents a scale for evaluating groups of parameters for each aspect of the Model. It is presented in Figure 4.

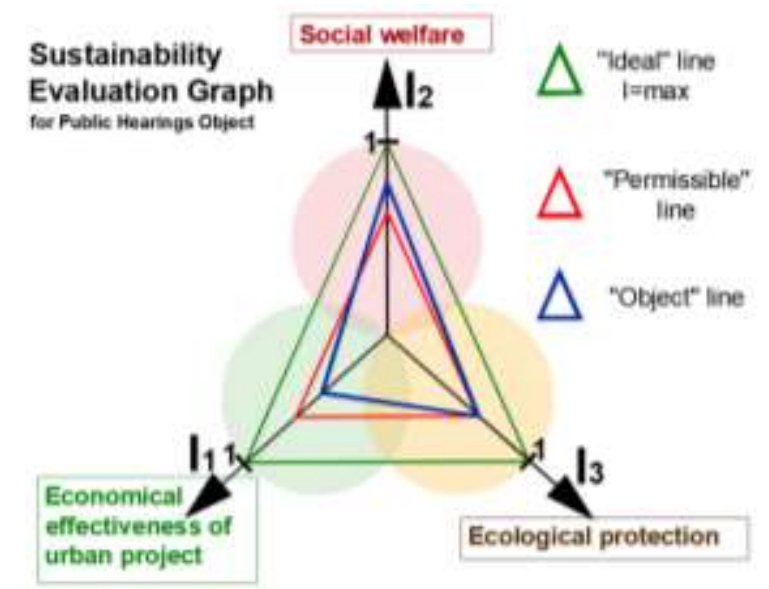

Fig 4. Sustainable evaluation graph.

The calculation of each of the integral parameters is made as the sum of its criteria according to the formulas presented in Table 1. 
Table 1. Calculation of integral parameters.

\begin{tabular}{|c|c|}
\hline Modal aspect assessment & Integral parameter calculation formula \\
\hline Economical effectiveness of urban project & $I_{1}=\sum_{1}^{m} \sum_{1}^{n} I_{1 m}^{n}$ \\
\hline Social welfare & $I_{2}=\sum_{1}^{m} \sum_{1}^{n=4} I_{2 m}^{n}$ \\
\hline Ecological protection & $I_{3}=\sum_{1}^{m} \sum_{1}^{n=4} I_{3 m}^{n}$ \\
\hline
\end{tabular}

It is necessary to distinguish 2 main sources for assessing the quantitative and qualitative parameters of the Model:

$\circ$ The objective assessment of the public hearing Project by urban planning specialists, which is expressed in evaluation of expert opinion, which is calculated by the method of qualimetry.

- The subjective assessment of the public hearing Project by ordinary citizens, which is expressed in formulating their opinion on the Project, made upon the results of the social survey by compiling the questionnaire on the Project.

An analysis of the presented grid related to the Model of public hearing Project sustainability shows various scenarios for laying the Project assessment lines:

- The green line is the line of the "ideal" sustainability of the Project, in which all aspects of sustainable development are $100 \%$ fulfilled;

- The red line is the line of the acceptable level of sustainability of the Project, which can be obtained from the analysis of implemented Projects assessed by both specialists and residents for the compliance of the Projects to Sustainable Development Model;

- The blue line is the design line, which is obtained from the calculation of integral indicators for a specific Project. Analysis of its placement in the grid will allow assessing the degree of sustainability of the Project and making a decision on the rationality of making changes to the Project of public hearings, its adoption or complete rejection.

\section{Results}

The present study proposes a method for an objective systematic assessment of urban planning decisions during public hearings on a system of parameters, each of which is evaluated according to a number of criteria. The advantages of this method are the following:

- Urban planning criteria are aimed at ensuring the sustainable development of territories in the interests of the city, its present population and future generations and are brief supporting materials on the object of hearings.

- The criteria are valid data on the object of hearings, presented in visual form: figures, statistical data, graphs. 
- These criteria are an objective response to the comments made by the population, as well as objective facts of the population's appeal on the project in case of their violation.

\section{Conclusion}

The reported study was funded by RFBR according to the research project № 18-01101004 and has the very great value for the development for our Russian urban management system. Public hearings of urban development Projects are an important stage of urban planning, when the city and its population interact. Public hearing is a necessary tool for the sustainable development of urbanized territories and the key to the formation of a highquality living environment for nowadays population and its preservation for future generations.

\section{References}

1. G. Rowe, L.J. Frewer, Technology\&Human Values (2013) DOI: $10.1177 / 016224390002500101$

2. E. Magnus, M.S. Knudtsen, G.Wist, D. Weiss, M. Lillefjell, Jour. of Public Health Research 5(2)-621, 60-67 (2016)

3. E. Rollason, L.J. Bracken, R.J. Hardy, A.R.G. Large, Jour. of Envir. Manag. 228, 267278 (2018)

4. I.V. Tkacheva, J. Pravo i gosudarstvo; teoria i praktika 10(46), 62-65 (2008)

5. O. Ejukova, Konstituzion. i municip. pravo 4, 63-67 (2010)

6. R.S. Fomin, Skif. vopr. stud. nauki 7(23), 55-58 (2018)

7. O.N. Pavlyceva, Conf. IPISCE, MSUCE, 555-558 (2017)

8. L. Li, X.H. Xia, B. Chen, L. Sun, Jour. of Cleaner Production 201, 499-506 (2018)

9. J. Peña, G. Nöldeke, Journal of Theoretical Biology 457, 211-220 (2018)

10. L. Bottini, Cities, 108-114 (2018)

11. S. Duleba, S. Moslem, Sustainability 10(10), 3647 (2018)

12. Z.I. Ivanova, Economica i predprinimatelstvo 8(73), 563-566 (2016)

13. Z.I. Ivanova, MATEC, 53, 08014 (2017)

14. Z.I. Ivanova, M.I. Afonina, IPISCE, MSUCE, 144-148 (2017)

15. T. Pristavec, Psychological Sciences and Social Sciences 73(8), 1457-1469 (2016) 